\title{
Flexural properties and Cost evaluation of hybrid polymer composites developed from different stacking sequences of fiber laminates
}

\author{
Ankit Dhar Dubey ${ }^{1}$, Jogendra Kumar ${ }^{1}$, Shivi Kesarwani ${ }^{1}$, Rajesh Kumar Verma ${ }^{l, *}$ \\ ${ }^{1}$ Materials and Morphology Laboratory, Department of Mechanical Engineering, Madan Mohan Malaviya University of Technology, \\ Gorakhpur- 273010, India
}

\begin{abstract}
The stiffness and reduced weight of polymer composites makes them unique from conventional manufacturing materials. The failure modes can vary from tension to compression dominated with the matrix interface. The mechanical strength can be improved with the stacking of different laminates for the development of hybrid composites. This study highlights the fabrication of laminate composite for flexural tests and analysis for stacking sequences of carbon (C) and glass $(\mathrm{G})$ fiber laminates. The fabrication was performed by a cost-effective hand layup method for laminate polymers to observe changes in the properties of the final composites. This work investigates the cost appraisal of the hybrid composites to replace the existing costly material (neat material). The results of flexural properties and experimental study of lowcost composite materials are present in this paper, which integrates an empirical analysis for manufacturing sectors. The cost-effectiveness of composite manufacturing is determining the best stacking configuration for optimal production cost. The proposed laminate composite can be recommended for structural applications, and the addition of different fabric layers could be helpful for the development of a costeffective product.
\end{abstract}

\section{Introduction}

Increasing demands in technical and traditional applications are now being observed for polymer matrix composites. Various studies demonstrated that the polymer products have high stiffness, strength, reduced weight, tailoring features, anti-corrosion, etc. Composite materials incorporate the properties of the various components to enhance the condition of the parent material and resolve the limitations. Another strategy that has been further established is to strengthen the impact of further developments with fiber reinforcement. For unique applications, the best way to replace traditional materials is in the form of hybrid composites. Hybrid composites have high tensile, young module, ultimate strain, and impact properties with costeffective preparation. Various reinforcements have different properties, i.e., carbon/glass/aramid fiber and nanomaterials in the final composite development. In the case of carbon fiber, it has high modulus strength, and it can be optimized with a low modulus like glass fiber. The supplement of stacking of different fibers such as carbon and glass fiber (CF/GF) could be helpful for hybrid composites.

Earlier investigations show the feasible mechanical properties of the hybrid composite material and the positive efficacité of the stacking sequence. A laminated combination of several reinforcements, such as Carbon, basalt, kenaf, and flax fibers, was utilized to fabricate the composites [1]-[3]. In supplement to glass fiber, other reinforcements have been used for research objectives, including jute fiber [4]. The hybridization effects of multiple reinforcement materials with matrix materials have improved the composite. The finding reveals that the stacking sequences provide structures with long-lasting application [5], [6]. The mechanical properties of hybrid laminates were determined by several laminate reinforcements' compositions and arrangements [7]-[9]. Lopresto et al. [10] explored the effect and flexural behavior of different stacking sequences for carbon/glass fiber in the series. Subagia et al. [10] examined the role of varying stacking configuration sequences on the change in flexural properties of hybrid laminated composites. They revealed that the proper sequence of the laminates could improve the mechanical properties. Manders et al. [11] have studied the tensile properties of hybrid glass/carbon fiber composites. The hybridization shows that the effect of the feature depends on the proportion of the two types of fiber. In inter-play sequencing, Dong et al. [12] studied the flexural properties of hybrid composite with epoxy (matrix) and Glass/Carbon fiber. They reported a decreasing trend in flexural strength value as glass layers replaced carbon laminates but a favorable influence on flexural strength simulation analysis due to the hybridization effect. Due to tensile loading, the mechanical properties and failure of hybrid composites were studied by Munoz et al. [14]. The study concluded that the addition of glass fiber increases fracture strain and energy dissipation during the fracture process. Miwa et al. [15] investigated the hybrid composite influence by the length of the reinforcement, such as Carbon and glass fiber. The investigation revealed that increasing the length of the reinforcing 
fiber could increase the tensile strength of the composites. Fariborz et al. [16] analyzed mechanism for intra-ply sequencing influenced the tensile properties of hybrid composites. Khatri et al. [15] researched glass fiber and graphite hybrid composites in a polyphenylene sulfide (PPS) matrix. The work concluded that the reinforced content improved the strain value. Naik [16] investigated the impact properties and damage response of glass-carbon/epoxy hybrid composite plates. This confirmed that the hybridization effect increased the impact properties. Vidal et al. [17] examined the effect of stacking layers of on hybrid carbon/glass/epoxy laminate composites. The hand layup technique is very cost-effective for preparing the composite structure with the matrix on the various fiber layer sequences [18], [19]. To reduce costs in the manufacturing of aeronautical components, hybrid composites are desired to replace carbon fiber composites in the future.

An in-depth evaluation of the stacking sequence is summarized in the introduction section. The review outcome has remarked that stacking reinforcement is an efficient method for developing cost-effective polymer composites. This paper highlights the fabrication of stacking composites and its cost analysis. The effects of two different reinforcements materials for developing hybrid carbon/glass fiber polymer composite are explored. An attempt has been made to propose a costeffective method for hybrid laminates composites having boosted flexural properties.

\section{Experimental}

\subsection{Materials}

Carbon fiber and glass fiber were bi-directional sheet (400 GSM, plain weave) reinforcing materials utilized to manufacture laminated polymer composites. The matrix component is epoxy (resin), and the binder material is used as a hardener.

\subsection{Sample preparation}

The epoxy is the significant component of the composite and provides the matrix phase of the hybrid composite. The matrix combination is prepared with epoxy and hardener for the fabrication of the hybrid composite. The ratio at which the constituents are blend is 10:1 (Epoxy: Hardener) parts by weight. The consolidated combination of epoxy and hardener was treated as a matrix of the composite structure. The properties of epoxy and reinforcements are given in Tables 1 and Table 2.

Hand layup was used to manufacture the composites according to the previously established cost-effective, environmentally friendly process that does not require any specific type of special equipment [20]. Fig 1 displays the schematic diagram of the fabrication process. A thin polyester sheet was placed on the top and bottom layers. Silicone spray was sprayed over the polyester film to avoid sticking for better and easy removal of the formed composites. The required sizes $(26 \mathrm{~cm} \times 17 \mathrm{~cm})$ of fiber sheets were cut, and each fiber was positioned manually in the open mold according to the different configurations decided. The prepared solution (epoxy and hardener) was brushed uniformly over the glass/carbon fiber sheet, with the alternate carbon/glass fabric sheet was placed. A steel roller was rolled with a mild pressure on the matrix composite layer to remove the air trapped. Different stacking sequences were prepared to identify the best possible sequence required for better mechanical properties. The composite was cured at room temperature. Composites specimen was cut down according to the ASTM standards (ASTM D-790) for flexural testing.

Table 1. Carbon and Glass fabrics properties

\begin{tabular}{|c|c|c|}
\hline Parameters & Carbon fiber & Glass fiber \\
\hline Woven style & Plain & Plain \\
\hline Density (g/cc) & 1.79 & 2.55 \\
\hline Weight (GSM) & 400 & 400 \\
\hline Thickness (mm) & 0.42 & 0.55 \\
\hline Orientation (Directional) & Bi-directional & Bi-directional \\
\hline
\end{tabular}

Table 2. Properties of Epoxy (Lapox L12).

\begin{tabular}{|c|c|}
\hline Tensile Strength (MPa) & $\mathbf{1 1 0}$ \\
\hline Tensile Modulus (GPa) & 4.1 \\
\hline Strain to failure (\%) & 4.6 \\
\hline Density (g/cc) & 1.16 \\
\hline Specific gravity (25 $\left.{ }^{\circ} \mathrm{C}\right)$ & $1.1-1.2$ \\
\hline Hardener & $\mathrm{K}-6$ \\
\hline Mixing ratio (Epoxy: Hardener) & $10: 1$ \\
\hline
\end{tabular}

\subsection{Specimen details}

From Fig 2, the layup sequences used were C8, containing 8 layers of carbon fiber in the epoxy matrix. G8 is having 8 layers of glass fiber in the epoxy matrix. C4G4 having 4 layers of $\mathrm{CF}$ on the bottom side and 4 layers of GF upper side. G4C4 consists of 4 layers of glass fiber on the compression side and 4 layers on the tensile side. C5G3 having a combination of 5 layers of Carbon and subsequently 3 layers of glass fiber. C3G5 has 3 layers of carbon fiber on the upper side and 5 
layers of glass fiber on the lower side. C6G2 having 6 layers of carbon fiber with 2 subsequent layers of glass fiber. CG consists of an alternative layer of carbon fiber and glass fiber with 4 layers of each fiber.

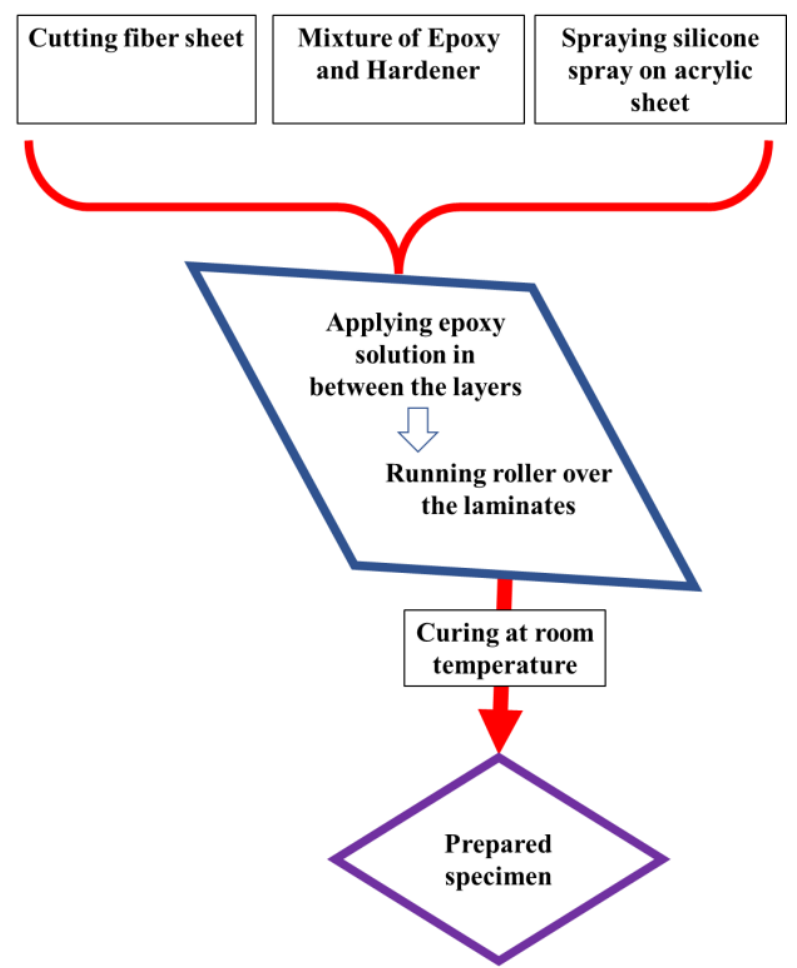

Fig. 1. Flowchart for sample fabrication.

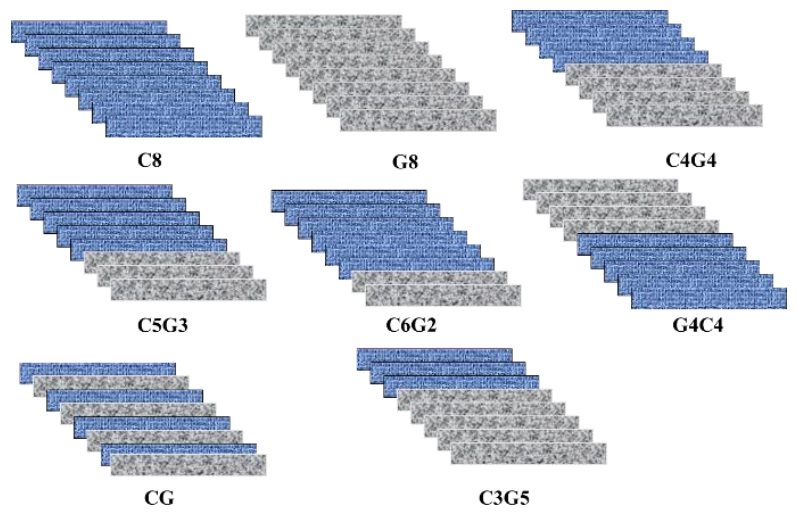

Fig. 2. Different stacking sequences.

\subsection{Flexural testing}

A three-point bending test was done for each composite sample with different stacking sequences. It was remarked that configuration $\mathrm{C} 4 \mathrm{G} 4$ has the same proportions and layers of carbon and glass fiber as that of G4C4; maximum load value and displacement value are very different from the latter. This shows that the properties of composites do not depend only on the proportions of the additional reinforcement used but also on the stacking sequence of the different layers of fibers used. This result has a similar consequence from the previous study. Subagia et al. [10] found that higher load value for hybrid composites and a higher value for composite with more carbon layers. Their results also suggest that two composites with the same composition but different sequences confirmed different results.
From Fig 3, the C6G2 hybrid structure has the highest flexural strength among all hybrid structures. C4G4 and C3G5 show a similar range of flexural strength, and both have four and three layers of carbon layers respectively on the compressive side and have good flexural value than $\mathrm{C} 5 \mathrm{G} 3$. The addition of glass fiber has increased flexural strength value, but in C6G2, top layers of carbon layers have added up the load value much more. Chen et al. [21] confirmed similar results that combining glass fiber layers increases the flexural strength relative to basalt fiber layers.

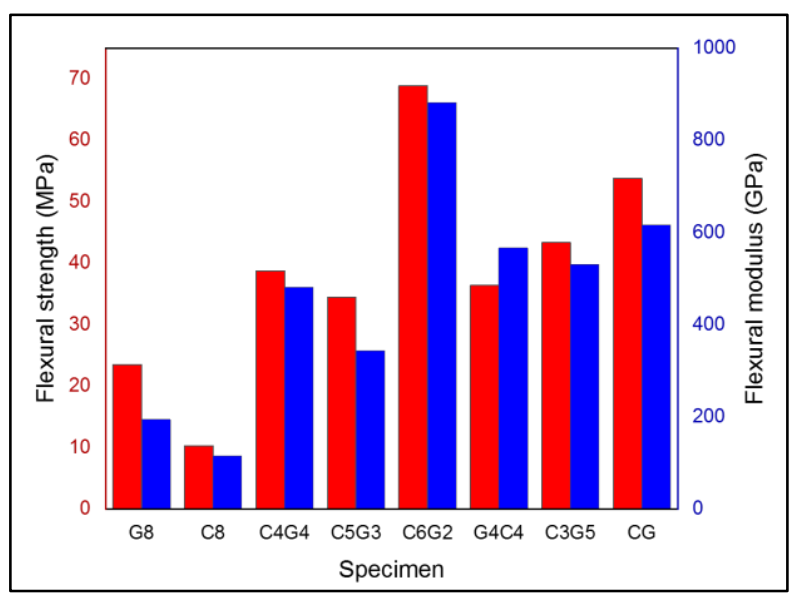

Fig. 3. Flexural strength and modulus of laminate composite with stacking sequences.

In increasing order of strength, $\mathrm{C} 6 \mathrm{G} 2>\mathrm{CG}>\mathrm{G} 4 \mathrm{C} 4>\mathrm{C} 3 \mathrm{G} 5>\mathrm{C} 4 \mathrm{G} 4>\mathrm{C} 5 \mathrm{G} 3$, it can see that $\mathrm{G} 4 \mathrm{C} 4, \mathrm{C} 4 \mathrm{G} 4$, and $\mathrm{CG}$ hybrid structures have 4 layers of each, but they all have different strength values. G4C4 has 4 layers of glass at the compressive side, and it shows a better load value than C4G4 having 4 layers of Carbon at the compressive side. CG composite having 4 layers of each but arranged in alternate order offers excellent value, second only to the C6G2 structure. This clearly shows the effects of sequencing on the flexural nature of the composite structure. In bending tests, the maximum impact is faced on the face or the compressive region of the composite laminates. As Carbon has high bending strength, placing the carbon layer on the top will produce better flexural results in the bending operation as they provide high resistance to the bending load. Similar results were confirmed by Jesthi et al. [27] that composites with carbon fibers outside show higher flexural modulus than Carbon in the middle layer. But it reduces the flexural extension of the composites. High resistance to load will make crack initiation a challenging job in the composite with carbon fiber in the top layer. In CG hybrid composite with carbon and glass layer placed alternatively, carbon layer on top will reduce the crack initiation and glass layer just beneath it will arrest it further, supported by the next carbon layer. The CG composites show perfect results in the flexural area. Also, this type of stacking sequence is preferable to other sequences with the same number of carbon and glass fiber layers. The flexural modulus likewise follows a similar pattern as flexural strength with little variety in the G4C4 structure. Both flexural strength and modulus 
have their highest values from $\mathrm{C} 6 \mathrm{G} 2$ hybrid composites. C4G4, G4C4, and CG hybrid structures are next in line with it.

\section{Cost analysis}

The second exciting aspect of this study is the cost analysis of the developed samples. Table 3 and Table 4 give the relative material costing for composites with different stacking sequences. Each cost was calculated as normalized to the cost of making $\mathrm{C} 8$ composite laminates [21]. Neat carbon composite was the most expensive, and neat glass fiber composite was the least costly among the fabricated composites. Fig 4 shows the bar chart with a plot of strength/cost and modulus/price of different composites for better understand the cost per sample development through the analysis of flexural strength outcome. It was found that the stacking C6G2 has the highest strength/cost and is one of the best values of modulus/cost among the hybrid composites. Along with that, CG, C3G5, C4G4, and G4G4 subsequently comes next in line, similar to the other properties discussed above.

\section{Conclusions}

The flexural test was performed on the different hybrid composite structures with varying stacking sequences to estimate the influence of stacking sequence and hybridization on the flexural properties of the proposed laminate composite. Based on the obtained results, the following conclusion can be drawn:

Table 3. Cost percentages of each composite.

\begin{tabular}{|c|c|c|c|}
\hline $\begin{array}{c}\text { Stacking } \\
\text { order }\end{array}$ & $\begin{array}{c}\text { Carbon fiber } \\
(\%)\end{array}$ & $\begin{array}{c}\text { Glass fiber } \\
(\mathbf{\%})\end{array}$ & $\begin{array}{c}\text { Cost } \\
\mathbf{( \% )}\end{array}$ \\
\hline $\mathrm{G} 8$ & 0 & 100 & 18 \\
\hline $\mathrm{C} 8$ & 100 & 0 & 100 \\
\hline $\mathrm{C} 4 \mathrm{G} 4$ & 50 & 50 & 58.91 \\
\hline $\mathrm{C} 5 \mathrm{G} 3$ & 62.5 & 37.5 & 69.25 \\
\hline $\mathrm{C} 6 \mathrm{G} 2$ & 75 & 25 & 79.5 \\
\hline $\mathrm{G} 4 \mathrm{C} 4$ & 50 & 50 & 58.91 \\
\hline $\mathrm{C} 3 \mathrm{G} 5$ & 37.5 & 62.5 & 48.8 \\
\hline $\mathrm{CG}$ & 50 & 50 & 58.91 \\
\hline
\end{tabular}

\begin{tabular}{|c|c|c|c|}
\hline $\begin{array}{c}\text { Stacking } \\
\text { order }\end{array}$ & $\begin{array}{c}\text { Cost } \\
\mathbf{( \% )}\end{array}$ & Mod/Cost & Strength/Cost \\
\hline G8 & 18 & 1.31 & 10.80 \\
\hline C8 & 100 & 0.10 & 1.15 \\
\hline C4G4 & 58.91 & 0.66 & 8.17 \\
\hline C5G3 & 69.25 & 0.50 & 4.96 \\
\hline C6G2 & 79.5 & 0.87 & 11.09 \\
\hline G4C4 & 58.91 & 0.62 & 9.62 \\
\hline C3G5 & 48.8 & 0.89 & 10.89 \\
\hline CG & 58.91 & 0.91 & 10.47 \\
\hline
\end{tabular}

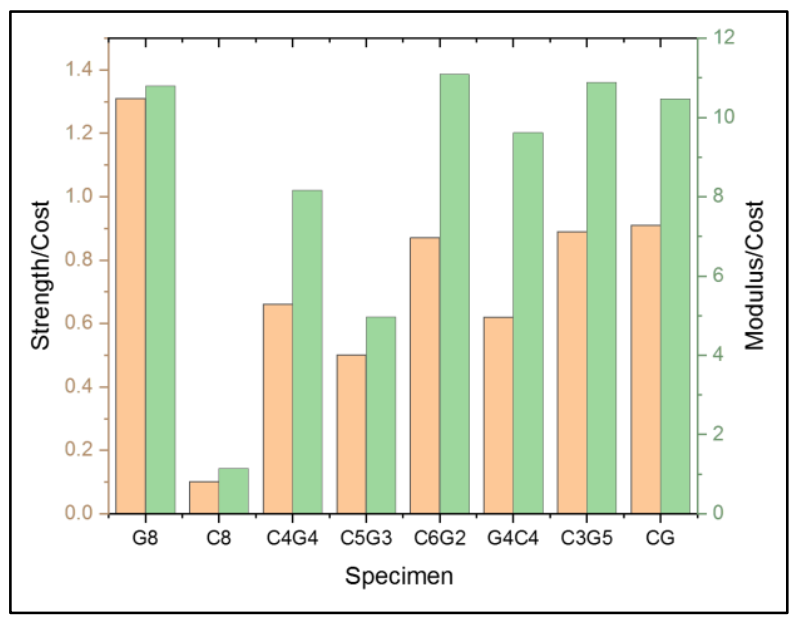

Fig. 4. Strength and modulus versus cost plot.

- Hybrid composite with C6G2 sequences produces highest flexural strength and flexural modulus with $\mathrm{G} 4 \mathrm{C} 4, \mathrm{CG}$, and $\mathrm{C} 3 \mathrm{G} 5$ configuration show next better values, respectively.

- Composite structures with the same proportion of different reinforcements such as C4G4, G4C4, and CG, each with 4 sheets of carbon fiber and glass fiber, show very different flexural properties. This indicates that stacking sequence plays a crucial role in the performance of the composite structures.

- With an increased hybrid ratio in the composite structure, there is an increase in the flexural strength and modulus of the composites.

- $\mathrm{C6G} 2$ has the best strength/cost and modulus/cost relationships, while CG, C3G5, C4G4, and G4C4 have good values.

Table 4. Strength and modulus versus cost data. 
- C6G2 shows the highest strength/cost and modulus/cost value ; this is the most economical configuration to be produced.

\section{References}

[1] A. Atiqah, M. A. Maleque, M. Jawaid, M. Iqbal, Compos. Part B Eng., 56, 68-73 (2014),

[2] E. Nisini, C. Santulli, A. Liverani, , Compos. Part B Eng., 127, 92. (2017)

[3] I. M. De Rosa, Express Polym. Lett., 5, 449 (2011)

[4] A. R. Bunsell, B. Harris, Composites, 5, 157 (1974)

[5] E. Sevkat, B. Liaw, F. Delale, B. B. Raju, Compos. Part A Appl. Sci. Manuf., 40, 1090, (2009),

[6] M. Sayer, N. B. Bektaş, E. Demir, H. Çallioğlu, Compos. Part B Eng., 43, 2152(2012)

[7] J. H. Song, Compos. Part B Eng., 79, 61, (2015)

[8] J. Zhang, K. Chaisombat, S. He, C. H. Wang, Mater. Des., 36, 75 (2012)

[9] M. A. Abd El-baky, Fibers Polym., 18,. 2417(2017)

[10] I. D. G. Ary Subagia, Y. Kim, L. D. Tijing, C. S. Kim, H. K. Shon, Compos. Part B Eng., 58, 251 (2014),

[11] P. W. Manders, M. G. Bader, J. Mater. Sci., 16, 2233 (1981)

[12] C. Dong, I. J. Davies, Compos. Part B Eng., 72, 65 (2015)

[13] R. Muñoz, V. Martínez, F. Sket, C. González, J. Llorca, Compos. Part A Appl. Sci. Manuf., 59, 93 (2014)

[14] M. Miwa , N. Horiba, J. Mater. Sci., 29, 973 (1994)

[15] S. C. Khatri , M. J. Koczak, Compos. Sci. Technol., 56, 181 (1996)

[16] N. K. Naik, R. Ramasimha, H. Arya, S. V. Prabhu, N. ShamaRao, Compos. Part B Eng., 32, 565 (2001)

[17] D. C. da S. M. Vidal, J. Heitor L Ornaghi, F. G. Ornaghi, F. M. Monticeli, H. J. C. Voorwald, M. O. H. Cioffi, J. Compos. Mater., 54, 731 (2020)

[18] M. P. Cavatorta, J. Mater. Sci., 42, 8636 (2007)

[19] L. Calabrese, G. Di Bella, V. Fiore, "Manufacture of marine composite sandwich structures," in Marine Applications of Advanced Fibre-Reinforced Composites, 57 (Elsevier Ltd., 2016)

[20] J. Kumar , R. K. Verma, “Experimental investigation for machinability aspects of graphene oxide/carbon fiber reinforced polymer nanocomposites and predictive modeling using hybrid approach," (Def. Technol., 2020)

[21] D. Chen, G. Sun, M. Meng, X. Jin, Q. Li, ThinWalled Struct., 142, 516 (2019)

[22] D. K. Jesthi, P. Mandal, A. K. Rout, R. K. Nayak, Procedia Manuf., 20, (530) 2018, 